\title{
Ferric reducing anti-oxidant power assay in plant extract
}

\section{Maruthamuthu Vijayalakshmi and Kandasamy Ruckmani}

Department of Pharmaceutical Technology, Bharathidasan Institute of Technology campus, Anna University, Tiruchirappalli 620-024. India.

Correspondence to Kandasamy Ruckmani at hodpharma@gmail.com

First Published: 1 June, 2016

DOI: $10.3329 /$ bjp.v11i3.27663

\section{ABSTRACT}

The ferric reducing anti-oxidant power (FRAP) assay involved the following steps: a) preparation of samples, b) reactions and c) finally measuring absorbance of sample and standard at $700 \mathrm{~nm}$ using spectrophotometer. The samples were methanolic extract, different fractions ( $n$-hexane, chloroform) and standard ascorbic acid. The solutions prepared were buffer solution ( $\mathrm{pH} 6.6), 1 \%$ potassium ferricyanide solution, $10 \%$ trichloroacetic acid and $0.1 \%$ ferric chloride.

\section{INTRODUCTION}

The total antioxidant activity can be measured by the ferric reducing antioxidant power assay (FRAP). The flavonoids and phenolic acids are present in the medicinal plant exhibit strong antioxidant activity which is depending on their potential to form the complex with metal atoms, particularly iron and copper. This method is based on the principle of increase in the absorbance of the reaction mixtures, the absorbance increases the antioxidant activity increases. The antioxidant compound present in the samples forms a colored complex with potassium ferricyanide, trichloroacetic acid and ferric chloride, which is measured at $700 \mathrm{~nm}$ by UV-Spectrophotometer.

\section{MATERIALS AND EQUIPMENTS}

- Deionized water

- Potassium ferricyanide

- Sodium chloride

- Potassium chloride

- Disodium hydrogen phosphate

- Potassium dihydrogen phosphate

- Hydrochloric acid

- Trichloroacetic acid

- Ferric chloride

- Centrifuge tubes

- Pipette

- Water bath

- Vortex shaker 
- Centrifuge

- UV-Spectrophotometer

\section{PREPARATION OF REAGENTS}

- 0.2M phosphate buffer (pH 6.6): $8 \mathrm{~g}$ of sodium chloride, $0.2 \mathrm{~g}$ of potassium chloride, $1.44 \mathrm{~g}$ of disodium hydrogen phosphate, $0.24 \mathrm{~g}$ of potassium dihydrogen phosphate was taken in a 1,000 mL standard flask and add $800 \mathrm{~mL}$ of distilled water and adjust the $\mathrm{pH} 6.6$ using hydrochloric acid and adjust the volume with deionised water.

- Potassium ferricyanide (1\%): $1 \mathrm{~g}$ of potassium ferricyanide was dissolved in $100 \mathrm{~mL}$ of deionised water.

- Trichloroacetic acid (10\%): $10 \mathrm{~g}$ of trichloroacetic acid was dissolved in $100 \mathrm{~mL}$ of deionised water.

- Ferric chloride (0.1\%): $100 \mathrm{mg}$ of ferric chloride was dissolved in $100 \mathrm{~mL}$ of deionised water.

- Ascorbic acid (0.1\%): $1 \mathrm{mg}$ of ascorbic acid was dissolved in $1 \mathrm{~mL}$ of water.

\section{VIDEO CLIP}

Ferric reducing anti-oxidant power assay: $21 \mathrm{~min} 18 \mathrm{sec}$

\section{METHOD}

- Different concentrations of the methanolic extract of $M$. serratulum and its various fractions (10-50 $\mu \mathrm{g} / \mathrm{mL}$ ) was added to $2.5 \mathrm{~mL}$ of $0.2 \mathrm{M}$ sodium phosphate buffer ( $\mathrm{pH}$ 6.6) and $2.5 \mathrm{~mL}$ of $1 \%$ potassium ferricyanide $\left[\mathrm{K}_{3} \mathrm{Fe}(\mathrm{CN})_{6}\right]$ solution.

- The reaction mixture was vortexed well and then incubated at $50^{\circ} \mathrm{C}$ for 20 min using vortex shaker.

- At the end of the incubation, $2.5 \mathrm{~mL}$ of $10 \%$ trichloroacetic acid was added to the mixture and centrifuged at 3,000 rpm for $10 \mathrm{~min}$.

- The supernatant $(2.5 \mathrm{~mL})$ was mixed with $2.5 \mathrm{~mL}$ of deionised water and $0.5 \mathrm{~mL}$ of $0.1 \%$ ferric chloride.

- The colored solution was read at $700 \mathrm{~nm}$ against the blank with reference to standard using UVSpectrophotometer. Here, ascorbic acid was used as a reference standard, the reducing power of the samples were comparable with the reference standard.

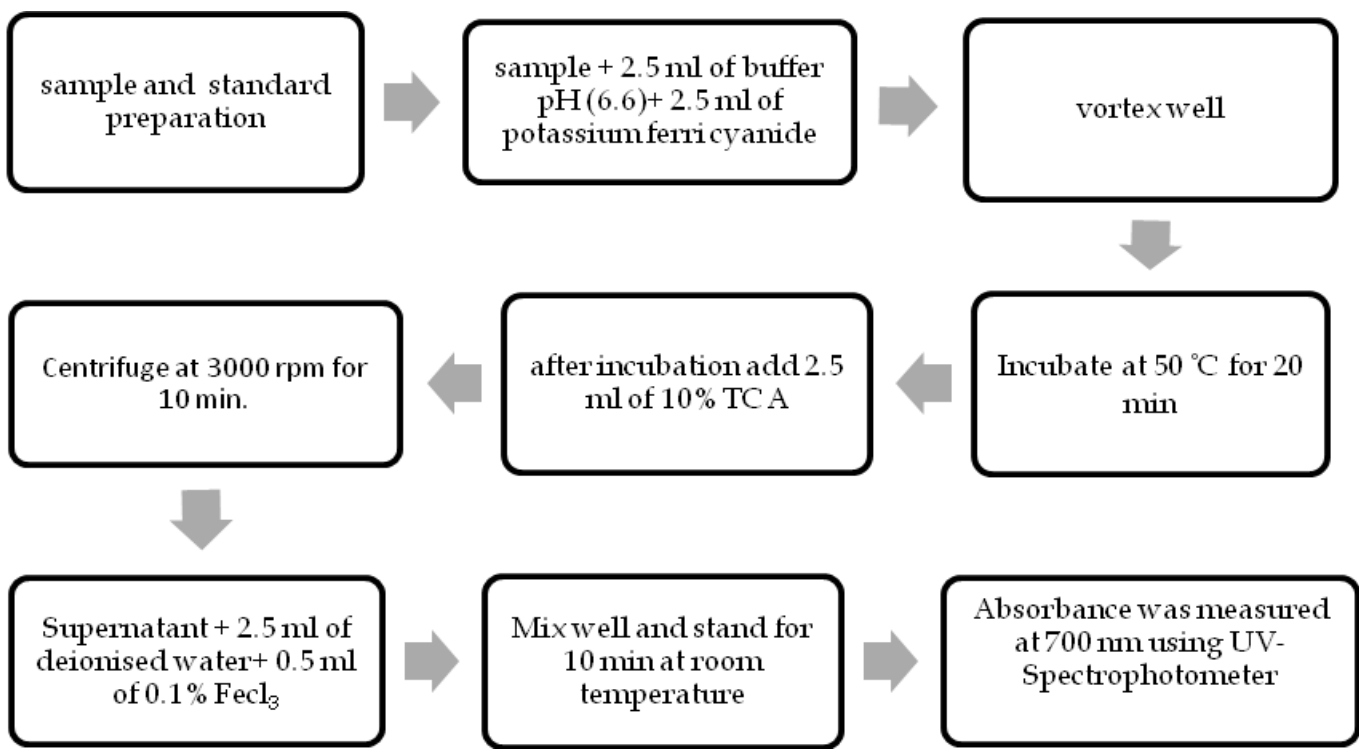




\section{DISCUSSION}

In this study, the reducing capacity of the extracts and fractions were performed using $\mathrm{Fe}^{3+}$ to $\mathrm{Fe}^{2+}$ reduction assay. In this experiment, the yellow color changes to pale green and blue color depending on the concentration of antioxidants in the samples. The antioxidants such as phenolic acid sand flavonoids were present in considerable amount in the extract of M. serratulum. All the samples showed reducing capacity in a concentration dependant manner.

\section{REFERENCES}

Oyaizu M. Studies on product of browning reaction prepared from glucose amine. Jpn J Nutr. 1986; 44: 307-15.

Do QD, Angkawijaya AE, Tran-Nguyen PL, Huynh LH, Soetaredjo FE, Ismadji S, Ju YH. Effect of extraction solvent on total phenol content, total flavonoid content, and antioxidant activity of Limnophila aromatica. J Food Drug Anal. 2014; 22: 296-302.

\section{PRECAUTION}

The solution must be prepared on the day of experiment and should be protected from sunlight. 


\section{Your feedback about this paper}

1. Number of times you have read this paper 0

2. Number of times you have seen the video clip 0

3. Quality of paper Click

4. Your comments

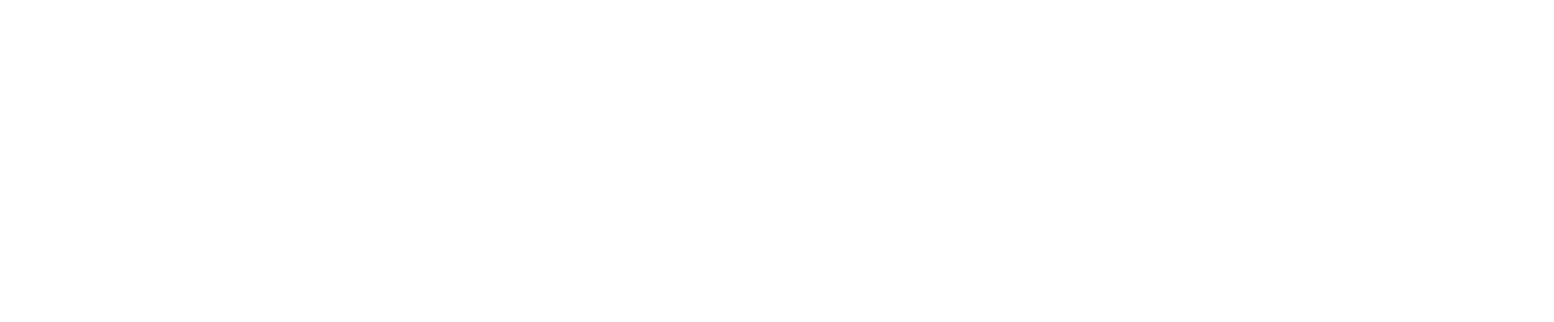

